\title{
Physician suicide still shrouded in secrecy
}

$\mathrm{S}$ uicide is an occupational hazard for doctors, but the profession still treats it like a "grubby little secret," says psychiatrist and physician health expert Dr. Mamta Gautam.

Medicine has the highest rate of suicide of any profession, Gautam told attendees at the recent Canadian Psychiatric Association annual conference in Toronto. She has treated doctors in distress for two decades and said most have lost a colleague to suicide. "It's not something we talk about or give the attention it deserves."

Doctors are twice as likely to kill themselves as members of the general public, Gautam said. Female physicians are up to four times as likely as other women to complete suicide. About 1 in 10 medical trainees report recent suicidal thoughts.

The question of why so many bright minds are driven to despair has haunted medicine for at least 150 years, said Gautam. Conventional wisdom chalks it up to stress; medicine is a tough job and some people can't cope. But Gautam said this explanation doesn't square with evidence that high achievers are particularly vulnerable to suicide. "This is not something that happens to the weak among us."

She argued that the problem is rooted in medical culture and toxic attitudes that prevent doctors from seeking help. "You can take any highly functioning, healthy person and put them in an unhealthy environment and they are going to become unhealthy. No one, not one person, is immune."

Medical culture rewards workaholics, demands perfection and glorifies self-sacrifice, Gautam said. Meanwhile, "we're not encouraged to talk about mental illness or share when we're struggling or overwhelmed."

Mental illness is a major factor in physician suicides, but only a quarter of doctors with symptoms seek help, she said. "There's a sense that we're weak somehow and a sense of shame and guilt with that."

Some doctors go to great lengths to

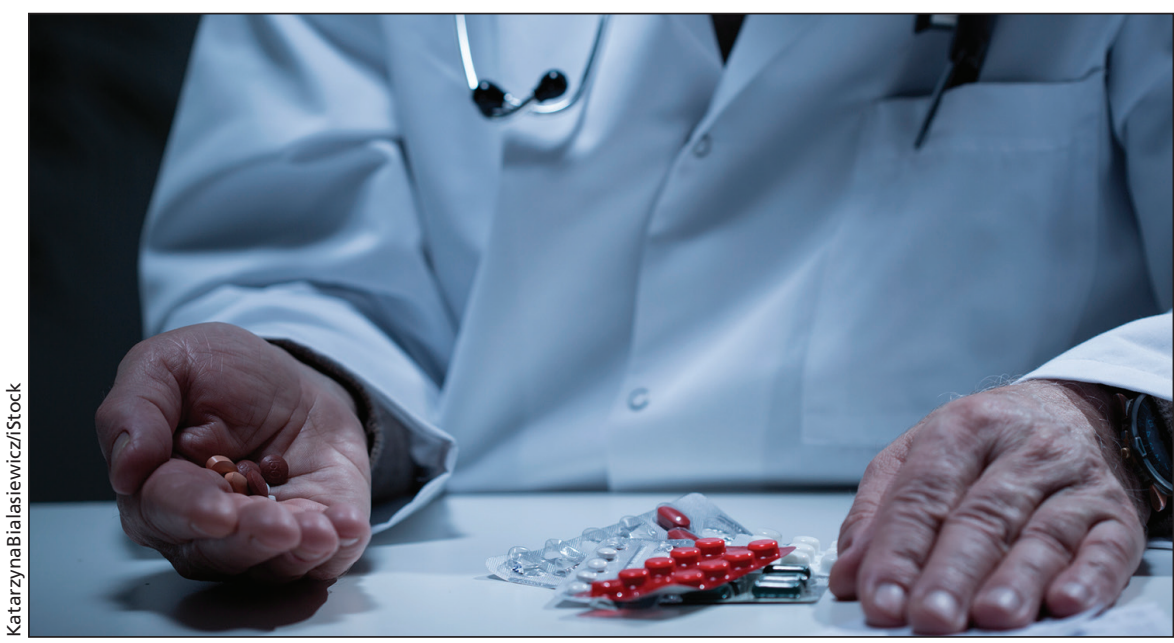

Most doctors have lost a colleague to suicide, psychiatrists heard at an annual conference.

hide their difficulties, fearing restrictions on their licence if word gets back to medical regulators. They use pseudonyms and pay for therapy in cash, or travel long distances to fill prescriptions they write for themselves.

Self-treatment is very common and likely underreported, Gautam said. "I did an audit of the last 100 doctors that I saw in my practice and I was shocked to find that 82 had started themselves on antidepressant medication."

According to Dr. Joy Albuquerque, associate medical director of the Ontario Medical Association's Physician Health Program, young doctors face particular pressure to hide personal struggles. "I worry about doctors now graduating with a lot of competition for jobs in certain areas and how people might make decisions about who gets jobs or not," she told CMAJ. "People are going to be expected to be perfect."

Gaps in research into physician health make it hard to combat stigma, she adds. For example, there is a lack of evidence showing how people with mental illness who return to work fare.

Still, Albuquerque says she sees signs that the culture of medicine is changing. "Recently, I had a doctor who had attempted suicide and survived, and that doctor was so pleased to be warmly greeted on return to work."
All of Ontario's medical schools now have wellness offices in place or under way. And in the past few years, individual physicians have started calling Albuquerque's office for help developing grassroots wellness initiatives at their workplaces. "I can come in and do grand rounds, and that's fine, but I think the traction is so much stronger when you have a champion there and it's something that's being built from within."

Meanwhile, there are "brave people" telling their stories," she said. "I think that's incredibly powerful."

Gautam noted that sharing personal stories of "competency, hope and recovery" are essential to change the way doctors view themselves and mental illness. "It's really important to foster awareness that physicians are normal and so we can be patients."

She also urged doctors to "assume that suicide is likely" among their ranks and not wait for colleagues in distress to ask for help. "We need to look for them because we know they are there."

Efforts to identify at-risk doctors need to be coupled with regulatory protections for those who disclose mental health problems, she added. — Lauren Vogel, CMAJ

CMAJ 2016. DOI:10.1503/cmaj.109-5337 